\title{
ACOMPANHAMENTO TERAPÊUTICO EM HOSPITAl DE REABILITAÇÃO FISIOTERÁPICA
}

\author{
Andressa Mariana Saldanha Elias $\star$
}

\begin{abstract}
RESUMO
Este artigo pretende mostrar como ocorre o acompanhamento terapêtico, as dificuldades encontradas e o cruzamento entre prática e teoria, a partir da experiência com um paciente fisioterápico. No texto discutiremos um pouco sobre transferência, contratransferência, cinco estágios sobre a morte e o morrer que foram cunhados por Kübler-Ross, e verificados no contexto hospitalar em pacientes fisioterápicos. Pensaremos os significados criados pela paciente a respeito da sua vida e corpo, a partir de uma visão antropológica de sua história. $O$ nosso relato será embasado e correlacionado às experiências de vida que levaram a paciente à angustia atual.
\end{abstract}

Palavras-chave: acompanhamento terapêutico; hospital; paciente fisioterápico; transferência; contratransferência.

\section{THERAPEUTIC MONITORING IN REHABILITATION PHYSIOTHERAPY HOSPITAL}

\begin{abstract}
This article intends to show what happens in a therapeutic nursing practice, expliciting the difficulties and the connections between practice and theory. Through the experience of nursing a patient, we are going to explain what can be considered nursing. In this text we are going to discuss about transference and countertransference during psychotherapy, five stages about the death, and to die considering Kübler-Ross's works, and verify them in a rehabilitation hospital's context. We are going to regard the patient's thoughts and how she deals with her life and her own body, concerned about her background. Our study is based and related to the patient's experiences that leads him to his state now.

Keywords: therapeutic nursing; rehabilitation hospital; patient; transference; countertransference.

\footnotetext{
^ Psicóloga. Pós-graduanda em Psicologia do Trabalho na Universidade Federal de Minas Gerais. Endereço: Universidade Federal de Minas Gerais. Departamento de Psicologia - Faculdade de Filosofia e Ciências Humanas. Av. Antônio Carlos, 6.627 - sala 4080 - Campus Pampulha - Belo Horizonte-MG. CEP: 31270-901.

E-mail: andressamariana@yahoo.com.br
} 


\section{INTRODUÇão}

O estágio no Hospital Paulo de Tarso teve a finalidade de realizar o acompanhamento terapêutico, levando os pacientes a uma melhor aceitação de suas condições físicas por conta de acidentes rotineiros, de Acidente Vascular Cerebral (AVC) ou de outras doenças que prejudicam o sistema- motor.

Esse acompanhamento aconteceu a partir de um vínculo estabelecido com o paciente, criando-se um envolvimento terapêutico. A empatia permite que o paciente confie e confidencie sua história de vida, possibilitando uma interferência positiva em casos onde não há uma perspectiva aparente de melhora. Esse acompanhamento tem a finalidade de levar o estagiário a presenciar a rotina do paciente em sua estadia no hospital. O foco terapêutico leva esse estagiário a identificar e a determinar as necessidades do paciente, suas dificuldades quanto à aceitação de sua debilidade física, levando o paciente a ter uma visão de mundo diferente, seguindo agora um novo padrão de vida, o qual the foi atribuído inesperadamente.

Os pacientes atendidos no Hospital Paulo de Tarso são assistidos pelo Sistema Unico de Saúde - SUS. É utilizado o texto de Cunha, J. e Cunha, R. (2001) como base para um melhor entendimento sobre o SUS e o atendimento realizado no hospital

Cunha, J. e Cunha, R. (2001) fazem uma classificação sobre os atendimentos realizados dentro do SUS, dividindo-os em atenção primária ou básica (realizado em postos de saúde), atenção secundária (atendimentos realizados em hospitais de acordo com a demanda do paciente) e atenção terciária (diz do equipamento específico existente no hospital para tratamento do paciente).

O foco principal do hospital Paulo de Tarso é a reabilitação fisioterápica, com equipamento e funcionários especializados para o trabalho. O hospital é classificado como de atenção terciária. No hospital há várias áreas de atendimento, nos importando principalmente a de psicologia, pois é a de atuação dos estagiários. São encontrados ainda fonoaudiólogos, fisioterapeutas, terapeutas ocupacionais e assistentes sociais que atuam em conjunto com os médicos, levando o paciente a ser visto não como uma doença ou simplesmente um corpo fragmentado, mas como um todo, com uma história de vida que o leva a ter certos comportamentos frente ao tratamento, à equipe e a todo o contexto hospitalar.

$\mathrm{Na}$ prática hospitalar, percebemos no paciente, por conta de seu estado de adoecimento, o apego à religião como um apoio para que consiga aceitar os fatos em sua vida, o que é visto pela equipe do hospital, como uma ajuda para a reestruturação do paciente em seu processo de melhora, levando-o a possibilidade de uma visualização positiva perante a experiência do adoecer e acarretando consequências em suas relações interpessoais.

Alguns pacientes não conseguem ter apenas a religião como apoio e necessitam de acompanhamento psicológico, assim, tentaremos explicar um pouco mais sobre o acompanhamento terapêutico, a transferência e a contratransferência, os estágios diante do adoecer, e uma possível reflexão sobre a 
tentativa de criar com a paciente um novo sentido sobre sua vida e seu corpo, partindo de dados sobre sua história de vida. Pensaremos ainda a religião como tendo um papel fundamental no processo de reabilitação ( a fé que os pacientes apresentam, ajuda na reabilitação).

Trabalharemos sobre o caso de Dona G, uma senhora de 52 anos que por conta de duas cirurgias para a retirada de um meningioma ${ }^{1}$ não tem condições de andar, mas acredita que conseguirá fazê-lo novamente.

\section{O Acompanhamento Terapêutico}

O acompanhamento terapêutico fundamenta-se na clínica (acompanhar) e não no assistencialismo (carregar). $\mathrm{O}$ acompanhante (estagiário) circula com o paciente no seu dia-a-dia dentro do ambiente freqüentado (hospital), visitando todas as alas por onde o paciente circula. Com essa participação, o acompanhante ajuda no desenvolvimento de novas atividades, ampliando o leque de ações e experiências, contribuindo para a recuperação de capacidades perdidas e aquisição de novas capacidades, além de ajudar o paciente na reflexão de suas dificuldades. Ajuda também na organização e desenvolvimento de metas e na reintegração ao meio social.

Dona $\mathrm{G}$ encontrava-se com poucos ganhos fisioterápicos, mas com muita força de vontade para adquirir mais autonomia e acreditando na possibilidade de voltar a andar. Durante o acompanhamento, o estagiário de psicologia tentou fazer a paciente se adaptar da melhor forma aos exercícios realizados dentro da fisioterapia, sempre atuando como representante terapêutico. Diante dos ganhos vistos pelo acompanhante, esse passou as informações para a psicóloga hospitalar com o intuito de pedir uma avaliação da terapia ocupacional (T.O), a fim de verificar a possibilidade de haver mais ganhos com a T.O. Como a psicóloga achou favorável esse acompanhamento, a paciente passou a ser assistida pelas duas equipes.

No livro Acompanhantes Terapêuticos e Pacientes Psicóticos, de Suzana Kuras (1987) vemos a existência de um tópico referente às funções do acompanhante terapêutico, que nos ajuda a pensar o acompanhamento - apesar da amostra ser diferente daquela do artigo. Algumas funções foram vivenciadas durante o trabalho realizado. Iremos citar e exemplifica-las a partir da prática realizada.

\section{Conter o paciente}

O acompanhante deve ser continente perante às ansiedades, angústias, temores e desesperanças vivenciadas pelo paciente, fazendo assim ele se sentir mais seguro perante às vivências e entendendo os sentimentos aflorados.

Durante um dia de acompanhamento a Dona G, o estagiário, chegando ao quarto, percebe a paciente angustiada e lhe pergunta o que se passa. Dona G diz que o maqueiro já havia passado chamando-a para a fisioterapia, mas ela não queria descer antes de conversar com a enfermeira sobre sua fralda que estava molhada. O acompanhante the informa que a enfermeira estava ocupada, pois esse era o horário utilizado para dar banho nos pacientes. Por não entender os dizeres do acompanhante, Dona $\mathrm{G}$ inicia um choro juntamente com uma lamuria 
sobre sua situação, dizendo "isto não aconteceria se eu estivesse andando", além de explicar o choro dizendo "sou muito nervosa". Como não entendera, mais uma vez a situação é explicada, além de ser ilustrada, sendo passado que esse tipo de situação não ocorre apenas com ela, mas também com outros pacientes. Neste momento Dona G se acalma e a enfermeira chega ao quarto lhe passando informações sobre a fralda utilizada. Ao chegar à fisioterapia, o acompanhante terapêutico percebe a paciente ainda preocupada com a fralda e tenta acalma-la, repassando os dizeres da enfermeira.

O acompanhante foi fundamental neste momento, pois conteve uma emoção aflorada, informando ser, a mesma, indevida por conta da situação em que a enfermeira se encontrava.

\section{RePRESENTAR O TERAPEUTA}

Este tópico fala sobre a inclusão do acompanhante nas atividades terapêuticas, ajudando na metabolização das interpretações feitas pelo terapeuta, neste caso seria nas atividades relacionadas ao físico e não ao psíquico: o terapeuta aqui são os membros da equipe hospitalar: fisioterapeutas, terapeutas ocupacionais, psicólogos, enfermeiros, técnicos de enfermagem, médicos e assistentes sociais.

Durante um acompanhamento de Dona G à fisioterapia, o estagiário percebeu que ela não havia entendido a explicação do fisioterapeuta sobre a causa de suas tonturas recorrentes e falta de firmeza no corpo. O acompanhante lhe explicou de uma forma simples, buscando elementos de seu conhecimento, realizando a explicação de forma concisa e esclarecedora, embasada em elementos retirados nas conversas iniciais sobre vida e experiência da paciente.

Com isso, constatamos que representar o terapeuta diz dos esclarecimentos que o acompanhante fornece para o paciente sobre dizeres realizados pelos "terapeutas", ou seja, ele trabalha sobre as elaborações realizadas pelo paciente, mas sempre de acordo com o foco buscado pelo "terapeuta".

\section{Atuar como agente Ressocializador}

O paciente perturbado sofre uma desconexão com o mundo. À medida que um vínculo afetivo com o acompanhante é criado, ocorre o mediar e reencontro com o mundo exterior do paciente.

No caso de Dona G, percebeu-se, por conta das cirurgias sofridas, a dificuldade de armazenar nomes e fatos ocorridos no presente, com isso percebemos uma falha em sua memória recente. A partir desta observação e como ela havia citado que sua filha mais velha sempre utiliza uma agenda para registrar fatos, compromissos, nomes e telefones, foi sugerida a paciente utilização de uma agenda para anotar estes ocorridos, fazendo assim com que os fatos sejam guardados de certa forma. 
Foi tentada também uma socialização dentro da instituição, já que suas companheiras de quarto não estarão mais presentes por conta da alta recebida e ela não tem contato com outros pacientes, pois sai do quarto apenas para ir até a fisioterapia e terapia ocupacional. Assim, foi sugerido que ela ficasse um tempo nos corredores do hospital para ter contato com outros pacientes.

\section{TransferênCIA}

Percebemos, durante o acompanhamento terapêutico, que não era necessário apenas fazer uso da empatia, mas também da transferência, que se coloca além da dimensão de trazer informações sobre a realidade para o paciente. A transferência é uma relação cordial, que prevaleceu durante o trabalho e foi além da empatia, ajudando na melhora objetiva em vários aspectos da doença, além de se apresenta como base para a criação do vínculo e posteriormente no acompanhamento terapêutico. Dona $\mathrm{G}$ inicialmente comparou a estagiária com suas filhas, utilizando posteriormente de outras demonstrações explicita da transferência nesse acompanhamento terapêutico. Percebemos isso através da preocupação de Dona $\mathrm{G}$ com a presença da estagiária no momento da fisioterapia e terapia ocupacional, além de demonstrações afetivas quando esta chegava, tendo maior abertura para falar dos conteúdos subjetivos e significativos de sua vida.

Apesar de Freud (1912), em seus dizeres, especificar a transferência como ocorrendo apenas no setting terapêutico, por conta de seu manejo técnico/terapêutico, observamos sua universalidade na atuação do psicólogo, psicanalista e no hospital.

No texto "Dinâmica da Transferência" (1912), Freud explica algumas séries já existentes como a imago paterna e a imago materna, que são vivenciadas na infầncia, fazendo o paciente ter sua catexia libidinal, parcialmente insatisfeita e pronta por antecipação, a ser levada para o terapeuta, aqui estamos a nos referir a um sujeito que se encaixa dentro do quadro da neurose.

A transferência como nos diz Carlat (2007), seria um re-encenar inconsciente de relacionamentos do passado do paciente. A transferência pode ser positiva na qual a paciente vê o terapeuta como uma figura admirada, lhe dando qualidades maravilhosas. Porém, há a transferência negativa, onde a paciente, por ter sofrido alguns maus-tratos na vida, não espera que o acompanhante a trate de forma diferente.

Na transferência entre paciente e terapeuta, vemos que o terapeuta será colocado em uma das séries da transferência já existentes, lhe doando afetos ou descaso. No nosso caso, observamos uma transferência positiva, até onde a paciente está a doar bons afetos e demonstrações da importância da estagiária ao acompanhá-la.

Apesar do acompanhante terapêutico não ser um analista, a transferência acontece durante o trabalho, por isso conhecimento sobre a transferência é essencial para que o acompanhante consiga maneja-la no momento em que a mesma ocorre, identificando-a como causadora de benefícios ou prejuízos ao paciente, pois caso a mesma esteja acarretando prejuízos o psicólogo do hospital deve ser informado para realizar uma intervenção. 


\section{ContratransferênCia}

Segundo Carlat (2007), a contratransferência se refere às emoções do terapeuta, sentimentos em relação ao paciente, de afeto ou descaso. Mackinnon, Michels e Buckeley (2008), falam do desafio existente dentro do hospital: a privacidade é comprometida por conta dos atendimentos serem feitos sob o olhar de outras pessoas e ocorrerem interrupções a qualquer instante, tanto por parte da equipe como de parentes do paciente.

A contratransferência diz especificamente de sentimentos do terapeuta (no caso, acompanhante terapeuta) sobre o paciente, ou seja: afetos que levam o acompanhante a tratar o paciente como alguém importante em sua vida e até sentimentos de desprezo, por ele lembrar de alguém que já fez algo para a pessoa do terapeuta.

Durante o acompanhamento inicial houve ansiedade por parte da estagiária, apresentando preocupações com questões subjetivas de sua existência e das pessoas ao seu redor, ficando envolvida com a paciente. Essa ansiedade foi estancada por conta da estagiária entender sobre as diferenças individuais existentes e que nem sempre o problema do outro pode tornar-se seu problema.

\section{Os estáGios de KüBler-Ross Vistos No ATENDIMENTo}

Durante o atendimento utilizamos como base a obra de Kübler-Ross (1996), Sobre a morte e o morrer: o que os doentes terminais têm para ensinar a médicos, enfermeiras, religiosos e aos seus próprios parentes, que descreve cinco estágios diante da morte e do morrer. É bom salientarmos que esses estágios são formas simbólicas de morte e morrer (em nosso caso referindo-se à morte simbólica de uma condição física).

No caso de Dona G, percebemos a passagem por alguns desses estágios. A seguir, iremos relatar sobre essas fases correlacionando-as com o caso clínico.

$1^{\circ}$ estágio - Negação e Isolamento: Na negação os pacientes consideram o fato do adoecimento e da morte, mas deixam de lado esses pensamentos para lutarem pela vida, sendo o lutar pela vida uma forma de ponderar com as escolhas e mobilizar medidas menos radicais. A negação não diz que o paciente não falará sobre os fatos ocorridos, mas que falará quando estiver preparado. O acompanhante deve saber o limite existente sobre este assunto, não o forçando a dizer.

A negação do paciente é uma defesa temporária, sendo logo substituída por uma aceitação parcial, mas assumir sua condição existencial não diz necessariamente de uma aumento da tristeza.

Muitas vezes durante a negação o paciente prefere se isolar, por conta das pessoas que sempre cobram uma conversa sobre o assunto. 
No caso de Dona G, por conta do meningioma, sequelas no sistema- motor geraram perda da movimentação dos membros inferiores, havendo da parte dela uma negação sobre o fato de não voltar a andar. Durante uma conversa sobre o assunto, relata sua preferência por não saber se ficará sem andar, pois se souber, desistirá da reabilitação. Com isso, foi respeitada a decisão dela e o assunto foi encerrado.

$2^{\circ}$ estágio - A Raiva: Este estágio vem logo após a negação, corresponde ao não assumir a situação presente. A paciente age como se houvesse outra resposta para o seu caso e que isso não ocorre com ela. Para o paciente os médicos não sabem nada e há um questionamento do porquê com ele e não com o outro.

No caso de Dona G, até o momento, não foi presenciada a existência deste estágio, mas esse fato não indica que ela não passara por ele.

$3^{\circ}$ estágio - Barganha: Diz de certo acordo para adiar o fato em si, o paciente, juntamente com a família, faz promessas, muitas vezes religiosas, para a situação melhorar e passar logo, tendo sempre o sentimento de que tudo vai dar certo.

A nossa paciente muitas vezes cita que Deus fará dela o que quiser, mas não sabemos se houve alguma promessa de sua parte e por parte dos seus familiares.

$4^{\circ}$ estágio - Depressão: O paciente entra em contato efetivo com a doença e suas perdas do corpo, das atividades e de seus objetos, e o momento de elaboração da vivência efetiva do luto.

Apesar de Dona $\mathrm{G}$ apresentar fala pessimista e pensarmos em uma depressão leve, a depressão exposta por Kübler-Ross, até o momento não foi vivenciada pela paciente, pois ela encontra-se em um estado de negação da realidade.

$5^{\circ}$ estágio - Aceitação: Pacientes que receberam apoio nas fases anteriores podem chegar a uma aceitação da situação e de sua vida, ou seja, uma aceitação de sua existência.

Durante todo o trabalho realizado com Dona G, buscou-se fazer com que ela aceitasse toda sua situação, mas esse trabalho não poderia ser realizado por conta de Dona G se encontrar no estágio da negação.

\section{Sentido}

Neste tópico, discutiremos sobre os sentidos já estabelecidos por Dona $G$ sobre seu corpo e vida.

\section{Corporal}

Segundo Vaz (2004), o corpo não é físico-biológico, mas sim a expressão do existir humano, pois através do corpo o homem consegue a autocompreensão e é através do corpo que o homem consegue se situar no espaço-tempo, organizando assim o seu estar-no-mundo. Somente através do corpo que o homem consegue visualizar-se como estrutura completa, ou seja, bio-psico-socio-espiritual. 
No caso estudado, observamos a questão de Dona G com sua perna, perpassando por toda uma história vivenciada com esta parte de seu corpo. Ela sempre se lamenta sobre os traumas já vivenciados com essa perna. Há momentos em que vemos Dona $G$ repassando toda sua angústia por não conseguir andar, por conta de ter quebrado o tornozelo da perna direita e dos vários traumas já acometidos nesse local.

\section{VIDA}

Durante todo o período de acompanhamento terapêutico, percebemos a escassez de elementos que auxilia Dona G a re-significar sua vida. Embora tenha conhecimento sobre a impossibilidade de andar novamente, ela continua na esperança de não mudar nada em sua constituição de vida.

Durante o acompanhamento, não tentamos fazer com que ela batesse de frente com essa questão, mas apenas sondamos para saber se ela teria consciência destes fatos, e tentamos fazer um trabalho que a ajudasse a ver o mundo com possibilidades.

\section{Conclusões}

Durante todo o trabalho de acompanhamento, tentamos estabelecer um vínculo de apoio para Dona G. Foi percebida uma pequena melhora de seu quadro durante todo o acompanhamento.

O estágio teve grande importância, pois mostrou mais uma forma de atuação do psicólogo no hospital e mostrou na teoria e na prática como pode ser feito o acompanhamento terapêutico.

O foco central do acompanhamento foi a visão que a paciente tem de si e como trazer a mesma para a realidade de que não será possível andar novamente. Porém, essa tentativa de trazê-la para realidade foi feita sutilmente e segundo os elementos que ela tinha para sustentar essa possibilidade, fazendo com que não fosse gerado um trauma maior que a leva-se a uma desorganização psíquica, podendo prejudicar todo o tratamento médico e o acompanhamento terapêutico.

\section{Nota}

${ }^{1} \mathrm{O}$ meningioma é um tumor que se desenvolve na meninge (bainha membranosa que envolve o cérebro e a medula) Sintomas como dores de cabeça, convulsões e cansaço são deferidos por conta da pressão exercida do meningioma no cérebro. Sua retirada é através de cirurgia, onde se deve tomar a precaução para não afetar zonas do cérebro importantes. 


\section{REFERÊNCIAS}

CARLAT, D. J. Entrevista psiquiátrica. Porto Alegre: Artmed, 2007.

CUNHA, J. P. P. da; CUNHA, R. E. da. Sistema Único de Saúde. In: BRASIL. Ministério da Saúde. Gestão municipal de saúde: textos básicos. Rio de Janeiro, 2001. p. 285-319.

FREUD, S. A dinâmica da transferência. In: . O Caso Schereber, Artigos Sobre Técnicas e Outros Trabalhos. In:__. Obras Psicológicas Completas de Sigmund Freud. Rio de Janeiro: Imago, 1912. v. 12, p. 52-57. Edição Standard Brasileira.

KÜBLER-ROSS, E. Sobre a Morte e o Morrer: o que os doentes têm para ensinar a médicos, enfermeiras, religiosos e aos seus próprios parentes. São Paulo: Martins Fontes, 1996.

KURAS, S. Acompanhantes Terapêuticas e Pacientes Psicóticos: o papel do acompanhante terapêutico no tratamento de pacientes psicóticos. Campinas: Papirus, 1987. cap. II.

MACKINNON, R. A.; MICHELS, R.; BUCKELEY, P. J.A Entrevista Psiquiátrica na Prática Clínica. Porto Alegre: Artmed, 2008.

VAZ, H. C. de L. Antropologia Filosófica. São Paulo: Loyola, 2004. v. 1.

Recebido em: 31 de maio de 2011 Aceito em: 10 de outubro de 2012 
